

Artículo de reflexión E12A07. * Recibido: 28.04.2018. * Aprobado versión final: 31.10.2018. JEL: D74, 171, K42, L71, L78, L79. * Pp. 213-233 * doi:10.33571/teuken.v10n14a10

\title{
Reflexiones sobre minería, post-acuerdo y territorialidad. \\ Relación con los nuevos escenarios del post-acuerdo en Colombia.
}

\section{Reflections on mining, post-agreement and territoriality.}

Relationship with the new post-agreement scenarios in Colombia.

\author{
Jorge Iván Ortiz Posada
}

\section{COLOMBIA}

Resumen: La implementación del Acuerdo de Paz, firmado entre el Gobierno de Colombia y las Fuerzas Armadas Revolucionarias de Colombia, requiere de nuevos escenarios productivos que tengan en cuenta la potencialidad económica de los territorios impactados por la guerra y la vocación económica de estos. La minería en Colombia es una actividad socio-económica que se ejerce en varias subregiones del departamento de Antioquia, Colombia impactadas por el conflicto armado y que puede contribuir a cerrar la brecha de inequidad. La minería mal hecha ha destruido ecosistemas y financiado grupos armados ilegales. Para la etapa de post-acuerdo se proponen proyectos mineros comunitarios autosostenibles en algunos territorios del departamento de Antioquia, Colombia donde tenían presencia las Fuerzas Armadas Revolucionarias de Colombia.

Palabras clave: minería; post-acuerdo; territorialidad.

Abstract: The implementation of the Peace Agreement, signed between the Government of Colombia and the Revolutionary Armed Forces of Colombia, requires new productive scenarios that take into account the economic potential of the territories affected by the war and their economic vocation. Mining in Colombia is a socio-economic activity that is carried out in several subregions of the department of Antioquia, Colombia, impacted by the armed conflict and that can contribute to closing the inequality gap. Poor mining has destroyed ecosystems and financed illegal armed groups. For the post-agreement phase, self-sustaining community mining projects are proposed in some territories of the Department of Antioquia, Colombia, where the Revolutionary Armed Forces of Colombia were present.

Keywords: mining; post-agreement; territoriality.

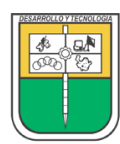

POLITÉCNICO COLOMBIANO JAIME ISAZA CADAVID
Jorge Iván Ortiz es Ingeniero Geólogo de la Universidad Nacional de Colombia. Ha trabajado en la exploración, explotación y beneficio de depósitos minerales, así como en la construcción de proyectos hidroeléctricos y formulación de proyectos mineros comunitarios. Actualmente, presta sus servicios en la Vicerrectoría de Extensión del Politécnico Colombiano Jaime Isaza Cadavid de Medellín.

Contacto: jorgeiortiz@elpoli.edu.co 


\title{
Reflexões sobre mineração, pós-acordo e territorialidade.
}

Relação com os novos cenários pós-convênio na Colômbia

\begin{abstract}
Resumo: A implementação do Acordo de Paz, assinado entre o Governo da Colômbia e as Forças Armadas Revolucionárias da Colômbia, requer novos cenários produtivos que levem em conta o potencial econômico dos territórios afetados pela guerra e sua vocação econômica. A mineração na Colômbia é uma atividade socioeconômica que é realizada em diversas sub-regiões do departamento de Antioquia, na Colômbia, impactada pelo conflito armado e que pode contribuir para o fechamento da desigualdade. A mineração deficiente destruiu os ecossistemas e financiou grupos armados ilegais. Para a fase pósacordo, projetos de mineração comunitários auto-sustentáveis são propostos em alguns territórios do Departamento de Antioquia, Colômbia, onde as Forças Armadas Revolucionárias da Colômbia estavam presentes.
\end{abstract}

Palavras-chave: mineração; pós-concordância; territorialidade.

\section{Introducción}

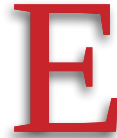

I post-acuerdo, periodo de tiempo que sigue a la superación total o parcial del conflicto armado con las Fuerzas Armadas Revolucionarias de Colombia (FARC), requiere de la implementación de propuestas productivas autosostenibles y pertinentes para cada territorio impactado por el conflicto armado. En algunos territorios de Colombia los proyectos mineros comunitarios son una excelente alternativa. La marginalidad, la inequidad, la ausencia de estado y la conformación institucional del país son algunos de los factores que han favorecido el nacimiento, reproducción y supervivencia de los grupos insurgentes y al margen de la ley. Las instituciones del Estado no han respondido eficientemente a las necesidades de la población y han perpetuado el vasallaje colonial, que sigue viendo a las entidades territoriales como periféricas y no como escenarios para concertar y generar, de abajo hacia arriba, un desarrollo sostenible, incluyente y colaborativo.

Las causas del conflicto armado y surgimiento de grupos al margen de la ley son múltiples: agresión oficial, pobreza y abandono estatal, fondos políticos partidistas, déficit institucional o ausencia de la misma, entre otras. El denominador común es la permanencia de un modelo de estado que, en materia de organización del territorio, no ha podido generar un desarrollo institucional adecuado para la redistribución de la riqueza.

La mayoría de los territorios del departamento de Antioquia, donde tienen o han tenido presencia grupos armados al margen de la ley, tienen vocación minera y/o potencial geológico para la presencia de yacimientos de minerales de interés. Los pobladores de estos territorios han ejercido la 
minería tradicional como actividad económica de sustento, de ahí que los proyectos que se formulen en la etapa de post-acuerdo para estas zonas deben considerar la implementación de proyectos agro-mineros, con actividades agropecuarias como complemento de la actividad minera. Formular proyectos solamente agropecuarios para estas regiones puede ser sinónimo de fracaso. Algunas experiencias exitosas sobre el desarrollo actividades mineras y agropecuarias es el registrado en el municipio de Frontino, Antioquia.

Los proyectos mineros comunitarios fortalecen la territorialidad de los municipios (entendida como el dominio o jurisdicción que posee un municipio o territorio). Su planeación y desarrollo tiene en cuenta las necesidades y fortalezas de los territorios, se articulan a la realidad del contexto, son intensivos en el empleo de recursos y mano de obra local y pueden ser propuestos desde los territorios.

La participación de las comunidades afectadas y de los territorios permite pasar de un gobierno central que orienta y define cuáles son las necesidades de los territorios, a un modelo que parte de lo local con participación, ejecución y presupuesto manejado y vigilado desde el territorio, con la intervención y acompañamiento del gobierno central. Estos proyectos fortalecen la democracia participativa y genera recursos para ser manejados e invertidos por los territorios.

\section{Características de la actividad minera en el departamento de Antioquia}

\section{Breve historia de la actividad minera precolombina y española en el departamento de Antioquia}

La vocación minera de Colombia data de épocas precolombinas. A la llegada de los españoles los pueblos indígenas explotaban importantes yacimientos auríferos vetiformes, como los de Buriticá en el departamento de Antioquía, oro aluvial en ríos y quebradas. Algunas comunidades indígenas eran maestros en el arte de la orfebrería, como los indios Quimbaya (que habitaron gran parte del eje cafetero y Tolima).

Vestigios de los primeros desarrollos mineros españoles se encuentran en el municipio de Buriticá del departamento de Antioquia. Los españoles entraron a Antioquia por la región de Urabá, donde fundaron algunos de los primeros caseríos en el continente americano. Cuando Alonso de Ojeda desembarcó en el Urabá construyó una fortaleza para guardar los pertrechos, caballos, armas y bastimentos que llevaba, en el mismo lugar en que años antes la había comenzado a fundar Juan de La Cosa. Es así como San Sebastián de Urabá, fundado en 1509 en la margen oriental del 
golfo del golfo, es el primer poblado en tierra de indias (consignado por el cronista Gomara). Este poblado fue abandonado y reemplazado por Santa María la Antigua del Darién, fundada en 1510 por Martín Fernández de Enciso y Vasco Núñez de Balboa, núcleo que ostentó el rango de ciudad y capital de castilla de oro y fue el asiento del primer gobierno español en tierra firme.

Desde la costa de Urabá los españoles avanzaron al interior y conocieron las ricas minas precolombinas de Buriticá, donde en la actualidad se explora y explota por una multinacional canadiense (Continental Gold) uno de los proyectos auríferos más ricos de Colombia. También en Buriticá se inician las primeras explotaciones dirigidas por españoles en el continente americano, donde son famosas las historias de María Centeno, mujer minera de origen español quién poseyó importantes minas en la zona.

\section{Relación de la minería aurífera y el conflicto armado en el departamento de Antioquia}

Los conflictos armados en Colombia han sido recurrentes. La violencia que encarnan tiene sus inicios desde la llegada de los españoles que, en búsqueda de oro y amparados en la evangelización, sometieron a sangre y fuego a pueblos indígenas. A principios del siglo XX las diferencias entre facciones liberales y conservadoras continúan. Entre 1899 y 1902 se da la guerra de los mil días (130.000 muertos); en 1930 y 1946 se generan confrontaciones entre campesinos y terratenientes por la tenencia de la tierra, y en 1948 se dio el "Bogotazo" por el asesinato de Jorge Eliecer Gaitán, con lo que se generalizan las revueltas en todo Colombia. Esta fase terminó en 1964 con 200.000 muertos.

La crisis económica de los años 60 por la caída de los precios internacionales del café y los conflictos de tierras dan cabida al surgimiento de la guerrilla. En 1964 se fundan los grupos guerrilleros de las Fuerzas Armadas Revolucionarias de Colombia (FARC) y el Ejército de Liberación Nacional (ELN), como grupos armados contra el gobierno, los terratenientes y los capitalistas.

En los años 80 y 90 surgen las Autodefensa Unidas de Colombia (AUC), grupos narco-paramilitares que se suman al accionar de las guerrillas. En 1991 se creó una nueva Constitución Política, con un componente ambiental e incluyente. Los gobiernos de Andrés Pastrana (1998-2002) y Álvaro Uribe Vélez (2002-2010) no lograron desescalar, ni mucho menos desactivar el conflicto. 
Durante el gobierno de Juan Manuel Santos, se iniciaron los diálogos entre el Gobierno y las FARC para solucionar el conflicto armado más antiguo de América Latina. En 2016 se firmó el Acuerdo General para la Terminación del Conflicto y la Construcción de una Paz Estable y Duradera.

Los puntos del Acuerdo de Paz son: Política de desarrollo agrario, participación política, fin del conflicto, solución al problema de las drogas ilícitas, verdad, reparación y justicia para las víctimas del conflicto armado e implementación, verificación y refrendación de los acuerdos. El Acuerdo firmado tiene un enfoque territorial que reconoce y tiene en cuenta las necesidades, características y particularidades económicas, sociales y culturales de los territorios. En ese sentido, la implementación del Acuerdo de Paz se hará desde las regiones y las comunidades, garantizando la sostenibilidad socio-ambiental con la participación de las autoridades territoriales y los diferentes sectores de la sociedad (Gobierno de la República de Colombia y Fuerzas Armadas Revolucionarias de Colombia, 2016).

En el departamento de Antioquia existe una relación entre la minería aurífera y las dinámicas del conflicto (ver los mapas 1,2 y 3). Según el Ministerio de Defensa, los grupos armados ilegales y las organizaciones criminales están presentes en, al menos, 30 municipios, donde hay minería de oro de pequeña escala no autorizada en el departamento (Ministerio de Defensa, 2015).

Como en el resto del país, el oro se ha convertido en una importante fuente de financiamiento para los grupos armados ilegales presentes en Antioquia (OCDE, 2016). En este departamento es común que los mineros tengan que pagar "la vacuna" (pago en dinero o porcentaje de mina que se realiza a un grupo ilegal, semanal o mensual o cuando se beneficie mineral), que constituye una extorsión o tributo, es decir, los grupos armados participan del negocio minero, como si fueran un socio o un costo más de su actividad productiva.

Según la Contraloría General de Antioquia (2013), las subregiones con mayores problemáticas ambientales, sociales y de ilegalidad, relacionadas con la minería, son: Bajo Cauca y Nordeste principalmente en los municipios de El Bagre, Nechí, Zaragoza, Tarazá, Amalfi, Anorí, Segovia y Remedios.

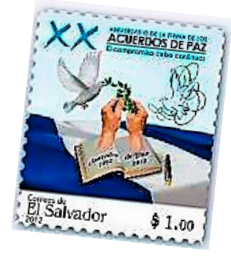




\section{8 -}

Mapa 1. Producción de oro en Antioquia

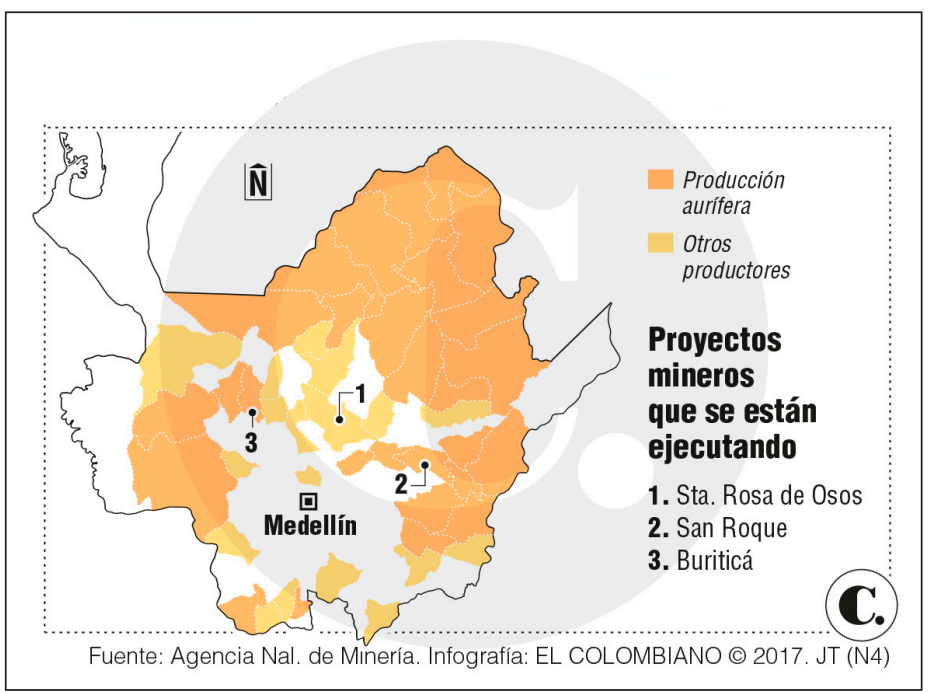

Fuente: Arias (2017).

Mapa 2. Minería ilegal en Colombia

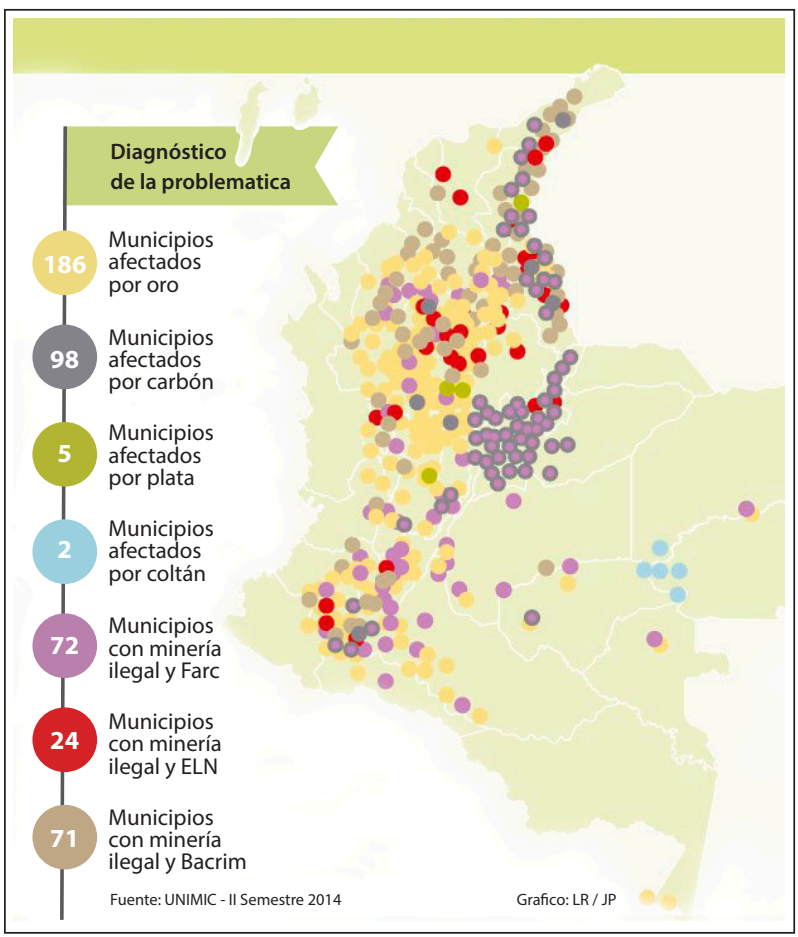

Fuente: UNIMIC-II (2014). 
Mapa 3. Presencia de las Autodefensas Unidas de Colombia en Antioquia

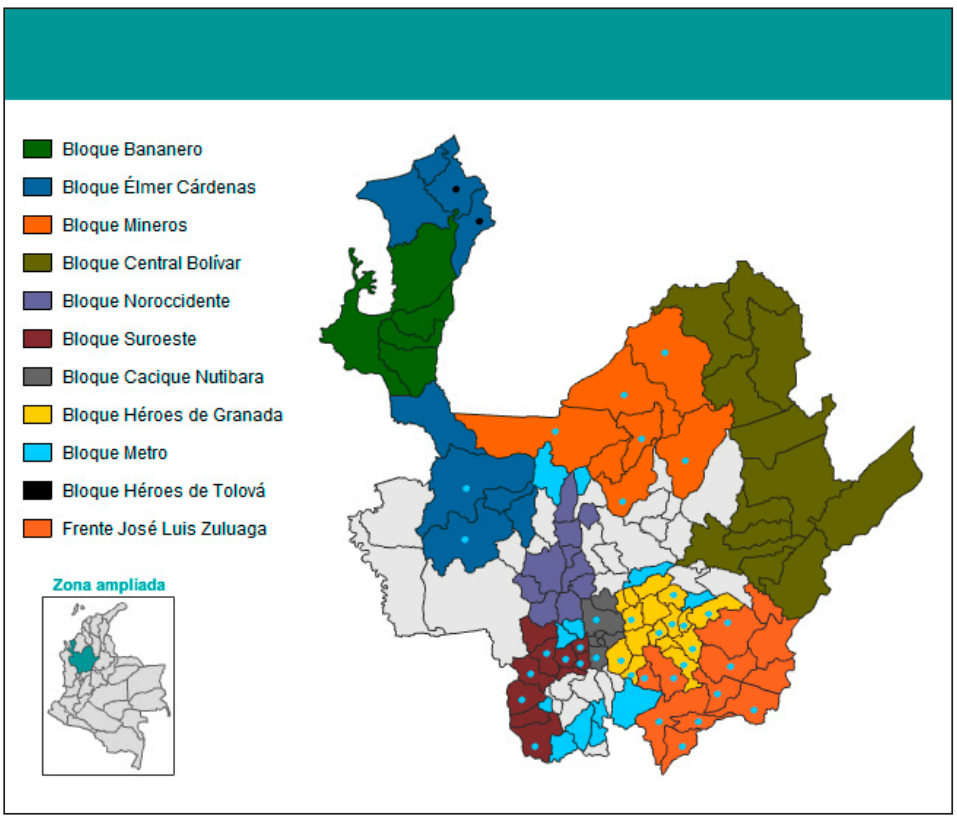

Fuente: UNIMIC-II (2014).

La minería ilegal es un tema social debido a que de esta se deriva el sustento diario de muchas familias. Es poco productiva, desaprovecha el recurso minero, incrementa la accidentalidad en las explotaciones y conlleva a la pérdida de recursos por la evasión en el pago de las regalías. La ilegalidad sirve de fuente de financiación a los grupos armados al margen de la ley y genera una problemática socio-ambiental de grandes proporciones, cuya solución en regiones apartadas urge la vinculación activa de los mineros tradicionales en el negocio minero para ejercer una minería autosostenible y en armonía con el medio ambiente.

Algunos mineros tradicionales, barequeros y chatarreros (palabra local para designar a grupos de mineros aluviales que benefician con batea las colas de los entables mineros) han militado en diversos grupos armados $\mathrm{y}$ deben ser considerados al momento de formular proyectos mineros $\mathrm{y}$ agroindustriales.

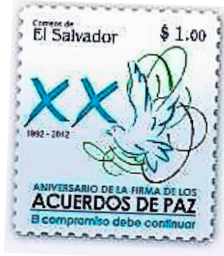


Mapa 4. Minería ilegal, actores armados y organizaciones criminales en Antioquia

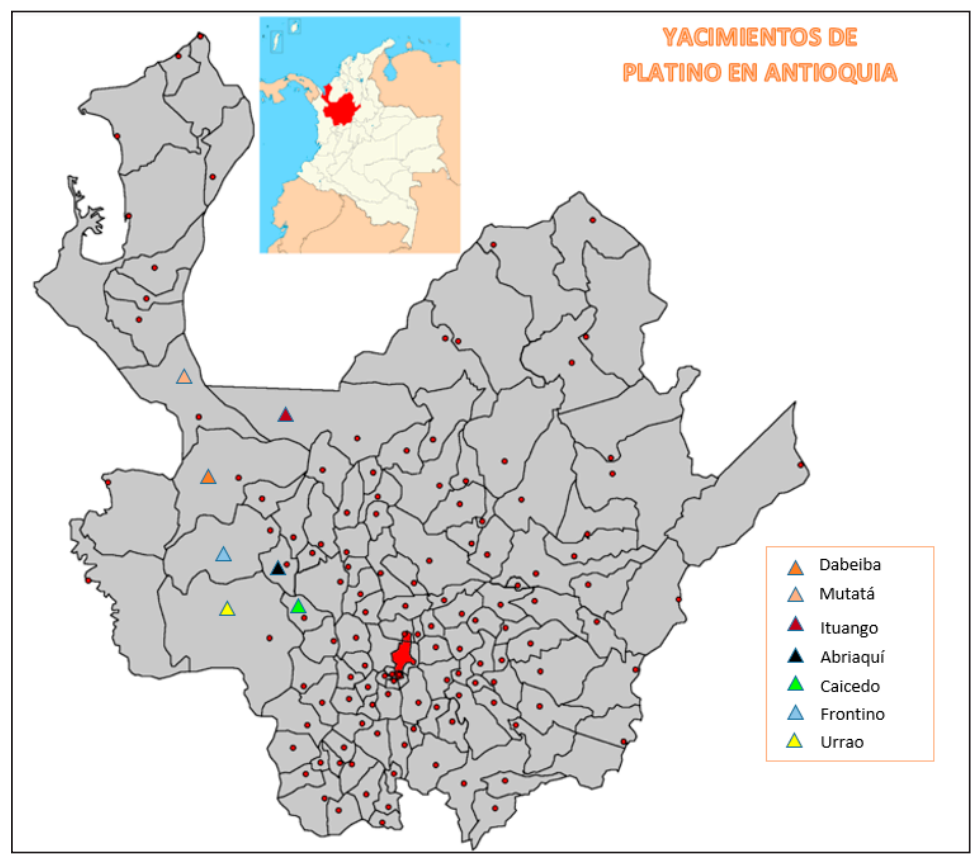

Fuente: OCDE (2016).

\section{Territorialidad de la minería y el conflicto armado con las FARC}

Los conflictos armados en Colombia tienen connotación territorial, con una directa relación de las áreas donde tienen presencia los grupos armados al margen de la ley y las áreas con producción minera y cocalera. Parte del financiamiento de estos grupos se hace con recursos provenientes de actividades ilícitas, y, parcialmente, licitas en el sector minero, ya que se conocen casos en que se amparan actividades mineras de grupos ilegales con contratos mineros legales.

En el Acuerdo de Paz no es explícito la consideración de todos los factores locales y la incorporación efectiva de los actores territoriales en las propuestas y proyectos. El post-acuerdo debe partir del reconocimiento de la territorialidad.

Las FARC han operado en 25 de los 32 departamentos de Colombia (ver mapa 5), con presencia en los Llanos Orientales, la Orinoquía; en los departamentos del Cauca, Caquetá, Putumayo, Valle del Cauca y Nariño; en el suroeste del país; en Chocó y Antioquia. 
Mapa 5. Áreas de coca, oro y presencia de las FARC.

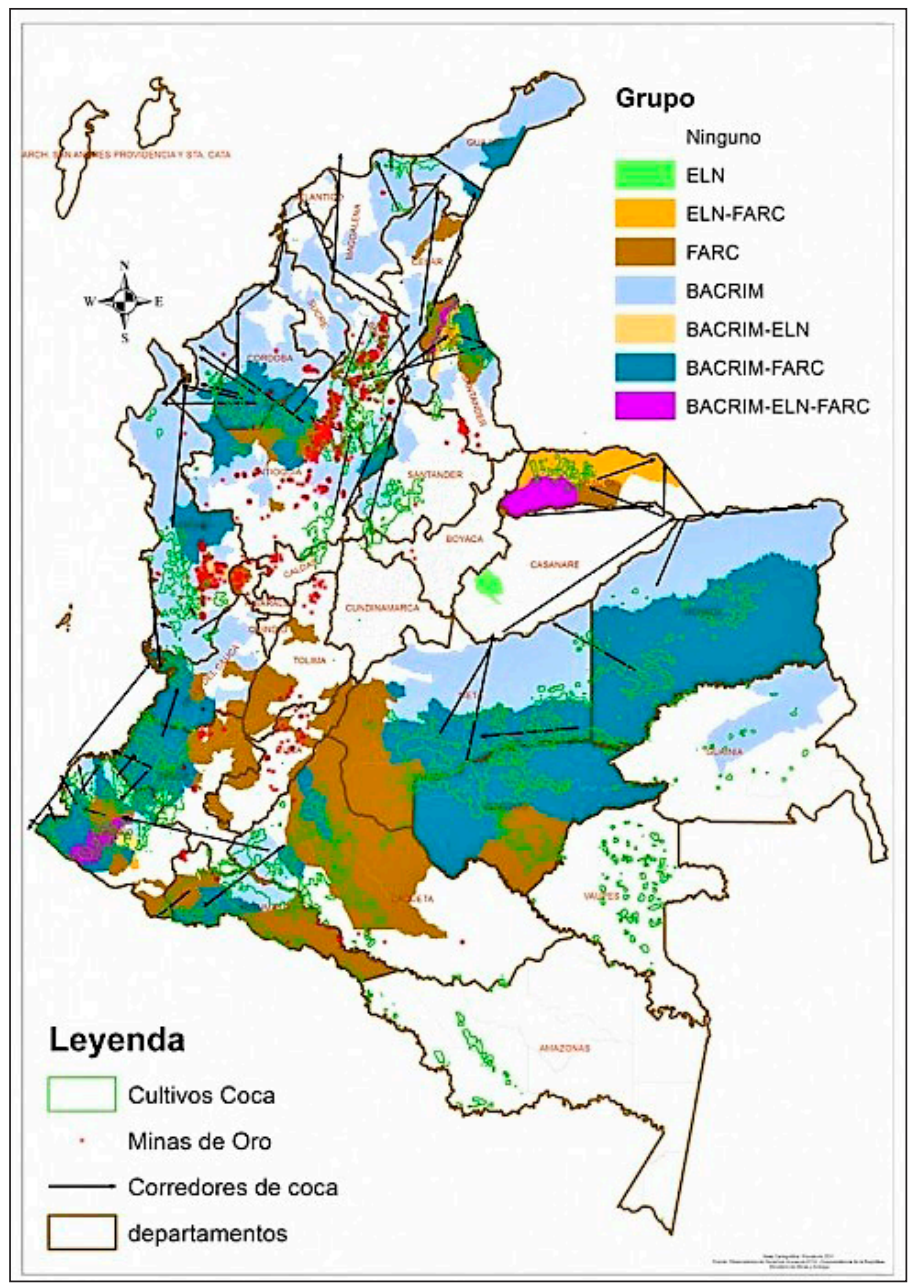

Fuente: Rocha y Escobedo (2013).

El mapa anterior muestra que las FARC han tenido cubrimiento nacional y presencia en zonas rurales alejadas de los centros urbanos, las cuales se caracterizan por difíciles accesos, escaza infraestructura, pobreza y ausencia del Estado. En el suroriente de Colombia (Llanos Orientales y Norte de la Amazonía), donde este grupo ha tenido fuerte incidencia, se explotan ilegalmente yacimientos de oro y coltán (cobalto-tantalita) con explotación de mano de obra indígena, allí hay tierras aptas para proyectos agroindustriales de gran envergadura. En la región andina antioqueña (zona montañosa) existen zonas con climas y suelos aptos para el desarrollo de proyectos mineros y agroindustriales. 


\section{Características de la actividad minera en Colombia}

Las características de la actividad minera en Colombia que tienen que ser tenidas en cuenta a la hora de formular proyectos mineros o agro-mineros en áreas impactadas por grupos armados en etapa de post-acuerdo son:

a. La minería es una actividad ancestral que se practica por los pueblos originarios desde mucho antes de la conquista española.

b. La Ley 685 de 2001 declara de utilidad pública e interés social la industria minera en todas sus ramas, es decir, pueden decretarse a su favor las expropiaciones de la propiedad de los bienes inmuebles que sean necesarios para su ejercicio y eficiente desarrollo.

c. La mitad de los grandes proyectos mineros en Colombia están sometidos a conflictos con comunidades (Observatorio de conflictos Mineros en América Latina).

d. La minería ilegal es una amenaza para el post-acuerdo. La mejor estrategia es la generación de proyectos legales incluyentes. En muchas zonas donde se realiza minería ilegal no se han realizado controles efectivos por la amenaza de grupos armados.

e. En Colombia existen cerca de 500.000 personas dedicadas a la minería informal (no criminal), que conforman cerca de 15.000 familias, quienes derivan su sustento de la minería. En las zonas rurales esta minería informal ocupa más personas que la minería formal. En el mundo la minería informal es ejercida por más de 10 millones de personas, que generan alrededor de 400 toneladas de oro anuales.

f. En Colombia hay aproximadamente 14.000 unidades de producción minera, de las cuales el 56\% carece de licencia de explotación.

g. En los municipios de Colombia donde se realiza la minería ilegal, las bandas criminales tienen presencia en 118 de estos territorios, las FARC en 87 y el ELN en 30 municipios.

h. Algunos grupos armados ilegales se han disfrazado a través de organizaciones agro-mineras para tener una base social.

i. En los últimos años se ha dado un desbordado licenciamiento minero, que ha afectado por igual a grandes latifundistas y a pequeños propietarios. En el licenciamiento minero rige el anacrónico principio de "primero en el tiempo, primero en el derecho", que ha ignorado a las poblaciones previamente asentadas y con arraigo en los territorios de interés minero. 
j. En algunas zonas mineras se desarrollan también cultivos ilícitos. La minería ilegal opera de forma muy similar al negocio de la coca y la cocaína. "La minería ilegal no ha desplazado al narcotráfico, por el contrario, se sirve de ella para el lavado de sus activos" Indepaz.

k. Existen algunos títulos mineros en los territorios étnicos, que son de propiedad colectiva.

I. El código minero de 2001 tiene un efecto negativo sobre los mineros artesanales. Eliminó las categorías de pequeña, mediana y gran minería, a las que recogió en las llamadas unidades productivas mineras, en las que están en igualdad de condiciones el pequeño minero y el gran inversionista.

m. Ha perdurado una debilidad en la institucionalidad minera, debido a que cada gobierno ha creado una institución minera desde la década de los años 60. A modo de ejemplo desde 1968 hasta el 2011 se han constituido 6 entidades en el ámbito minero.

n. El costo del postconflicto puede costar 187 billones de pesos, casi la mitad del PIB del país, para extenderlo en 10 años, la mitad correspondería al programa rural y la otra mitad a gastos de reparación.

o. El postconflicto se desarrollará principalmente en municipios y caseríos que actualmente ocupan las FARC, en zonas alejadas y aptas para la minería y la agroindustria. La minería en zonas de influencia de este grupo puede generar recursos importantes para el desarrollo social y la inversión en programas para el cumplimento de los acuerdos de paz.

p. En zonas mineras apartadas no existen controles efectivos en la cadena de valor del material aurífero, en particular en la comercialización.

q. La minería posee cobertura nacional, se ejerce en la región y en el campo, es intensiva en generación de mano de obra directa, con buena remuneración.

r. Muchas zonas donde se ha concentrado el accionar de los grupos insurgentes tienen vocación minera. Ha existido relación más que espacial entre las zonas mineras y las cocaleras.

s. La actividad minera en Colombia se realiza, en mayor medida, en condiciones técnicas y tecnológicas inadecuadas.

t. La ley minera contempla la figura de Áreas de Reserva Especial, que da prelación a los mineros tradicionales para obtener contrato especial de concesión. Figura muy útil para la formulación de proyectos comunitarios. 


\section{Potencialidad para el desarrollo de proyectos mineros comunitarios}

El departamento de Antioquia produce cerca del 50\% del oro del país. El Ministerio de Minas y Energía de Colombia declaró algunos distritos mineros, que son zonas estratégicas con continuidad geográfica y geológica, donde la minería es una actividad económica de interés e impacto social, cuya planeación y gestión se realiza con énfasis en lo territorial y empresarial. Los beneficios que se plantean son la sostenibilidad ambiental, el aprovechamiento óptimo de los recursos mineros, la creación de empleo directo e indirecto formal, la maximización del valor agregado, el estímulo al desarrollo regional y la articulación sostenible de los sectores económicos del territorio, en el marco de una nueva ruralidad (Ministerio de Minas y Energía, 2009).

En Antioquia se declararon cinco distritos mineros (ver mapas 6 y 7): Amagá (principalmente carbón), Nordeste y Bajo cauca (principalmente, oro), Frontino (principalmente, oro, calizas y cobre), Puerto Nare (calizas, oro, entre otros), Oriente Antioqueño (oro, calizas, entre otros).

Mapa 6. Distrito minero del Nordeste y Bajo Cauca

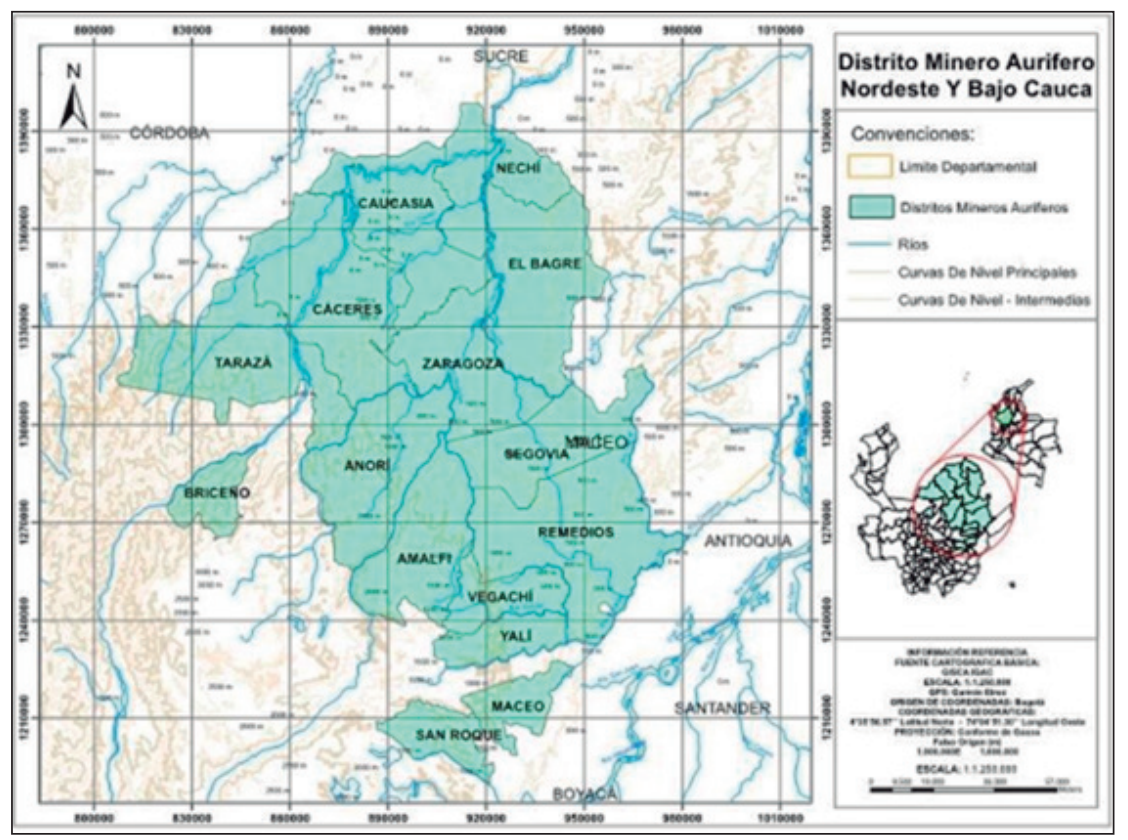

Fuente: Unidad de Planeación Minero Energética (2014). 
Mapa 7. Distrito minero de Puerto Nare.

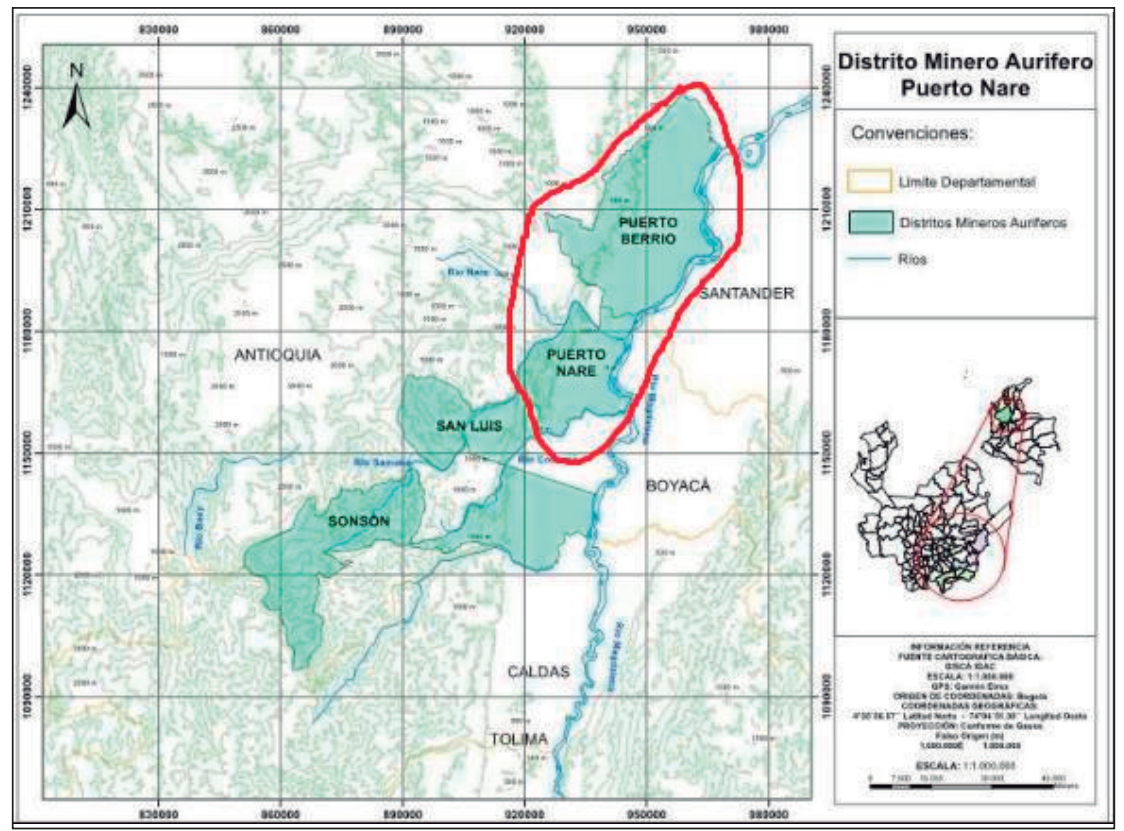

Fuente: Unidad de Planeación Minero Energética (2014).

Al comparar los mapas 6 y 7 con los mapas anteriores, los distritos mineros se encuentran en zonas impactadas por el conflicto armado. Las ventajas que ofrecen los distritos mineros deben articularse a los proyectos mineros agroambientales propuestos.

Geológicamente, el departamento de Antioquia está conformado por diversos tipos de rocas (ígneas, metamórficas y sedimentarias) de diversas edades, muchas rocas han sido intruidas por cuerpos ígneos, algunos de tamaño batolito como los llamados batolito de Segovia (distrito minero del Nordeste donde se ubican las ricas minas de Remedios, Segovia y El Bagre) y Batolito Antioqueño (muchos de los pueblos ubicados en él se fundaron inicialmente como comunidades mineras: Guarne, Marinilla, San Roque, Santa Rosa de Osos y otros). Varios cuerpos ígneos han aportado soluciones ricas en metales preciosos, principalmente auríferas, donde se han explotado numerosas minas de veta (ver mapa 8).

En ambientes sedimentarios recientes se han concentrado grandes depósitos aluviales auríferos en los municipios de Taraza, Cáceres, Caucasia y El Bagre, entre otros. En general, muchos de los ríos de Antioquia tienen importantes yacimientos auríferos, que han sido explotados de manera irracional, ocasionando deterioro ambiental. 
Mapa 8. Mapa geológico del departamento de Antioquia



Fuente: Ingeominas (2001)

En ambientes volcánicos sedimentarios con presencia de intrusivos y en ambientes de melange se tienen los ricos depósitos de Buriticá, cuyas vetas presentan altísimos tenores de oro.

En el Noroccidente de Antioquia existe un gran potencial minero en los municipios de Frontino, Cañasgordas, Dabeiba, Mutatá, entre otros. En esta subregión se encuentra el Distrito minero Frontino.

El Occidente de Antioquia presenta los distritos mineros relacionados con platino y oro en: 
- Distrito minero Dabeiba: Agrupa los municipos de Dabeiba, Uramita, Mutatá e Ituango. Comprende el depósito aluvial del Riosucio.

- Distrito minero Centro: Agrupa los municipios de Abriaquí, Caicedo y parte oriental de Frontino y Urrao, y los depósitos aluviales del Río Herradura y Río Pabón.

- Distrito minero de Mandé: Agrupa los municipios de Dabeiba, Frontino, Urrao, Murindó, y los depósitos aluviales de Carauta-Chaquenoda y Arquía-Penderisco.

Por su parte, en el Distrito minero del Nordeste de Antioquia se ubican los ricos yacimientos vetiformes de Segovía, Remedios, El Bagre, Amalfi y Anorí. La subregión Suroeste de Antioquia cuenta con yacimientos de pórfidos oro cobre y oro en Titiribí, Fredonia, Caramanta y Jericó, asociados a los intrusivos neoterciarios relacionados con el sistema de fallas CaucaRomeral.

En el Suroriente de Antioquia tambien se ha desarrollado una importante actividad minera aurífera en los municipios de Nariño, Sonsón y Argelia. Su potencial para los yacimientos diseminados (tipo pórfido) de cobre, molibdeno, oro es positivo (sur del municipio de Nariño). Por último, en la subregión del Bajo Cauca de Antioquia se encuentran los depósitos aluviales y yacimientos vetiformes en varios municipios.

En cuanto a depósitos no metélicos, la presencia en Antioquia es prolífera. Merece destacarse la presencia de grandes yacimientos de materiales pétreos, arcillas industriales (Oriente antioqueño), carbón (suroeste, Nororiente y Urabá), caliza (Noroccidente de Antioquia).

\section{Algunas consideraciones territoriales para el desarrollo de proyectos mineros}

La presencia de las FARC y el ELN en varias regiones de Colombia ha favorecido la conservación de bosques prístinos, al no permitir la entrada de la industria de explotación intensiva. En estos territorios no se ha realizado explotación minera intensiva a mediana y gran escala, a excepción de los depósitos auríferos y auroplatiníferos en Antioquia, Chocó y el oriente del país.

Uno de los grandes problemas ambientales se da en los sistemas de beneficio de oro por la contaminación con mercurio. Existen tecnologías de punta como los ciclos cerrados aplicando nanotecnología en el proceso de cianuración que, además de reducir considerablemente el consumo de cianuro, incrementan la recuperación de oro entre un $10 \%$ y $15 \%$ respecto al sistema de cianuración tradicional, reducen los impactos ambientales 
y pueden hacer que ciertas operaciones mineras en condiciones difíciles sean viables. Esta tecnología consiste en una formulación magistral para cada clase de mena, que podría aplicarse también a pequeños o medianos proyectos mineros en zonas alejadas; igualmente, se están desarrollando productos biodegradables sustitutos del mercurio y el cianuro.

A esto se suma el reto estatal de la transferencia de conocimiento a algunos territorios, que podrían constituirse en polos de desarrollo científico, tarea que hace parte del deber misional de las universidades y que bien lo pueden cumplir en el departamento de Antioquia instituciones universitarias públicas de orden departamental como el Politécnico Colombiano Jaime Isaza Cadavid, el Tecnólogico de Antioquia y la Universidad de Antioquia, acompañadas por la Universidad Nacional de Colombia y universidades privadas del departamento.

La minería social autosostenible como fuente de desarrollo económico territorial debe estar acompañda por la ciencia, la tecnología y la innovación para generar desarollo económico y social basado en el conocimiento y reconocimiento de la territorialidad para redistribuir la riqueza. Como lo plantea el documento Conpes 3582 (2009: 2):

El conocimiento no solo tiene la capacidad de resolver problemas de carácter científico o empresarial; este tiene un alcance mayor en la medida que ofrece soluciones a la sociedad en general. Con el fin de hacerla partícipe en el desarrollo científico y tecnológico del país, la cuarta estrategia de política consiste en promover la apropiación social del conocimiento, a través de su difusión en medios de comunicación y formación de mediadores de CTel (ciencia, tecnología e innovación), así como el apoyo a entidades que cumplen con esta labor.

Esto constituye un camino para insertar en la estrategia de desarrollo nacional a las regiones. Potenciar el desarrollo de la minería en el departamento de Antioquia en cumplimiento del post-acuerdo permite focalizar la acción del Estado en el desarrollo de un sector estratégico.

El sistema de administración centralista que actualmente impera en Colombia se ha caracterizado por ser ineficiente y disfuncional a nivel territorial, debido a la gestión inequitativa con los territorios, que en la mayoría de los casos no ha considerado las soluciones que se proponen desde el ámbito local.

La posibilidad para que prospectos mineros lleguen a ser minas, depende, en gran medida, del potencial geológico, el cual es particular y único en cada región; además, es premisa de obligatorio cumplimiento que la operación minera (desarrollo, explotación y beneficio) sea económicamente rentable, es decir, no basta solamente con que 
exista mineral de interés. La pregunta clave que se podría hacer es: ¿Es económicamente rentable extraerlo y beneficiarlo, teniendo en cuenta todas las variables, incluyendo los costos ambientales?

La creencia de los pequeños mineros es que "donde hay oro, hay una mina", lo que a la luz de la afirmación del párrafo anterior no es cierto, es por ello que se deben evaluar técnicamente los proyectos teniendo en cuenta las variables geológicas, caracterización de la mena, clase y categorización de reservas, beneficio, costos de exploración, explotación y beneficio. Es muy importante analizar la posibilidad de cerrar ciclos con el mineral de interés, es decir, hacer minería con valor agregado e impacto territorial.

Un gran problema de la minería en Colombia $y$, en general de Latinoamérica, es que se ha limitado a producir minerales commodities, pero no productos con valor agregado. Un gran contraste que se da en la minería aurífera es que, a pesar de su gran producción, las regiones donde se desarrolla son muy pobres. Debe propenderse, entonces, por generar productos con valor agregado (por ejemplo, la joyería), que en parte suplan los costos de producción en zonas marginales y alejadas de los centros de consumo.

Un punto crítico a resolver es que muchas áreas poseen titulación por particulares para exploración minera. Por ejemplo, en el departamento de Antioquia cerca del $80 \%$ del territorio está en solicitud y existen más de 1 530 hectáreas con títulos minero, lo que resta capacidad de exploración por otros. Se propone que las zonas mineras del post-acuerdo tengan un trato especial, donde la figura de Áreas de Reserva Especial puede tener aplicación.

La Constitución Política de 1991 propone fortalecer las entidades territoriales, pero la ley y la jurisprudencia continúan privilegiando la idea de unidad de país sobre la autonomía territorial, restringiéndola y controlando sus gastos. Algunos nudos críticos en el tema de la territorialidad, que se pueden destacar son:

a. La ausencia de reconocimiento sobre la diversidad nacional y la falta de adecuación de las instituciones a la idea de unidad en la diferencia.

b. La democracia participativa en el ámbito local carece de las herramientas eficaces para controlar a sus autoridades en el ámbito local.

Los nuevos escenarios deben considerar las características propias de cada región, para partir del fortalecimiento de las instituciones locales, consolidar la autonomía territorial, implementar y desarrollar procesos 
de paz territoriales con iniciativas propias que se enlacen con el Estado. Se plantea que el nuevo ordenamiento territorial exige un diseño institucional diverso y plural.

Las comunidades y autoridades territoriales deben ser tenidas en cuenta, reconociendo por su interés territorial y participación en las decisiones que les competen. La agro-minería social debe ser consultada con las comunidades donde técnicamente sea viable realizarla.

Una primera línea de acción prioritaria en el desarrollo de una política de ordenamiento territorial en función del manejo de áreas mineras en el post-acuerdo es crear y fortalecer los escenarios de concertación entre las autoridades centrales y las territoriales. Si la guerra ha sido territorial, la paz también debe serlo.

Estado no es sinónimo de nación, también son estado los departamentos y los municipios. El municipio es la entidad fundamental de la división política administrativa del estado (artículo 311 de la Constitución Política), y le corresponde promover la participación comunitaria y ordenar el desarrollo de su territorio, es decir, entre los usos del suelo y la propiedad del subsuelo los municipios tienen derechos como ente territorial y como entidad fundamental del Estado. El ordenamiento del territorio y los usos el suelo se fundamenta en la función social de la propiedad, la prevalencia del interés general sobre el particular y la distribución de las cargas y los beneficios (Ley 388 de 1997).

En Colombia los territorios presentan sectores altamente conflictivos como la minería, el medio ambiente y lo rural, por lo que es imperativo fortalecer la participación social comunitaria en todas sus formas y ámbitos. Varios de los puntos del Acurdo de Paz son deberes constitucionales del Estado que se han incumplido por décadas. La paz debe construirse desde los territorios; las propuestas y proyectos deben partir de lo local para generar empoderamiento territorial.

Los nuevos escenarios exigen una visión compartida, un cambio en los actores y en las relaciones del Estado con la sociedad civil y los territorios para avanzar hacia una mayor autonomía y mejor gobernanza territorial.

Augusto Trujillo y Guillermo Pérez (2016) afirman que buena parte de los conflictos y violencias están unidos a carencias o insuficiencias institucionales en los territorios y plantean la hipótesis de la multicausalidad. La ilegalidad minera es producida por los desajustes en el ejercicio del poder entre la nación y los territorios, por lo que parte de las razones de muchos conflictos mineros están en el inadecuado modelo de ordenamiento territorial que ha profundizado la recentralización. 
Es perentorio entonces dinamizar el proceso descentralizador, donde el Gobierno Nacional no sea el dueño del saber frente a lo territorial, sino una de las partes activas del aprendizaje que exige el nuevo escenario. Los programas y proyectos deben ser pertinentes y adecuados para las realidades y necesidades locales, es así como podrían implementarse proyectos agro-mineros exitosos.

Existe la posibilidad de hacer desarrollo minero sostenible en regiones apartadas, si se revierten las irracionales condiciones que han prevalecido hasta hoy, las cuales son las causas para que se desarrollen condiciones de inequidad y prosperen los grupos armados al margen de la ley. No es la minería per se la que ha creado impactos negativos en el medio ambiente, es el manejo por parte de ciertos grupos de poder.

\section{Propuesta}

En el Departamento de Antioquia deben formularse y desarrollarse proyectos mineros a escala social con procesos que generen valor agregado, los cuales son una excelente alternativa económica y social para impactar favorablemente a los territorios con potencial minero que han sido dominados por grupos armados. Al ser actuaciones concretas en territorios específicos constituyen una respuesta inmediata para controlar y mitigar los efectos que las economías ilegales han dejado en ellos.

Los procesos de valor agregado deben realizarse en los territorios, con objeto de transferir conocimiento y tecnología y crear nuevas fuentes de empleo. Esto ayudaría a que población desplazada y reinsertada se incorpore a la actividad laboral en sus territorios de origen y/o concentración, y que el valor agregado haga atractivo y rentable estas economías, las cuales requieren un dinamizador que, contando con los recursos que brinda el territorio, ayude a sustituir las economías ilegales que han imperado en dichos territorios.

La educación y capacitación pertinente en temas ambientales, agropecuarios, mineros, empresariales y de liderazgo, es transversal y debe partir de las necesidades de cada territorio, contando siempre con la participación de las comunidades.

Esta propuesta plantea el gran reto que tiene el Gobierno Nacional frente a las solicitudes o contratos de particulares que existen en las áreas de interés para el desarrollo de proyectos mineros sociales, situación que, legalmente y con la premisa de utilidad pública e interés social, debe resolver el Estado con el concurso de los particulares en favor de los proyectos agro-mineros. 


\section{Referencias bibliográficas}

1. ARIAS, Ferney. (2017). Tres minas paisas aumentarán en $163 \%$ extracción de oro legal. Disponible en Internet: https://www.elcolombiano.com/negocios/ tres-minas-paisas-aumentaran-en-163-extraccion-de-oro-legal-JE6556496 Consultado 27.09.2017.

2. COLOMBIA. Asamblea Nacional Constituyente. Constitución Política de Colombia, 1991.

3. COLOMBIA. Congreso de la República. Ley 388 de 1997. Bogotá, 18 de julio de 1997.

4. COLOMBIA. Congreso de la República. (2001). Código de Minas, Ley 685 de 2001. Bogotá, 15 de agosto de 2001.

5. COLOMBIA. Consejo Nacional de Política Económica y Social. Política Nacional de Ciencia, Tecnología e Innovación. Documento Conpes 3582. Bogotá, 27 de abril de 2009.

6. COLOMBIA. Contraloría General de Antioquia. (2013). Informe especial. Minería ilegal. La explotación ilícita de recursos minerales en Colombia. Casos Valle del Cauca (Río Dagua) - Chocó (Río San Juan). Efectos sociales y ambientales. Disponible en Internet:

7. https://www.contraloria.gov.co/documents/20181/198738/Separata-Mineriallegal.pdf/4d3d5cbe-4bda-430a-831e-ef2f6bbf5d0d?version=1.0

8. Consultado 21.08.2017.

9. COLOMBIA. Gobierno de la República de Colombia y Fuerzas Armadas Revolucionarias de Colombia-FARC. (2016). Acuerdo Final para la Terminación del Conflicto y la Construcción de una Paz Estable y Duradera. Disponible en internet: https://www.jep.gov.co/Paginas/Normativa/Acuerdo-Final.aspx Consultado 21.12.2017.

10. COLOMBIA. Ministerio de Defensa. (2015). Memorias al Congreso 2014-2015. Disponible en Internet:https:/www.mindefensa.gov.co/irj/go/km/docs/ Mindefensa/Documentos/descargas/Prensa/Documentos/memorias2014-2015. pdf Consultado 05-09.2017.

11. COLOMBIA. Ministerio de Minas y Energía. (2009). Memorias al Congreso 2009-2010. Disponible en Internet: http://servicios.minminas.gov.co/ documents/10180/23400/03-minas2009-2010.pdf/52d0c538-7af9-4394-b4fb73768ffa62e1 Consultado 19.12.2017.

12. COLOMBIA. Unidad Nacional de Intervención contra la Minería Criminal-UNIMIC. (2014). Disponible en Internet https://www.eltiempo.com/archivo/documento/ DR-870260. Consultado: 18.07.2017 
13. INGEOMINAS. (2001). Mapa geológico del departamento de Antioquia. Disponible en Internet:http://190.109.167.188:83/imagenes/SIAD/LI_GEO_ EST_DOC_MEMORIA_MAPA_GEOLOGICO_ANTIOQUIA_INGEOMINAS.PDF Consultado 25.09.2017.

14. OCDE. (2016). Debida diligencia en la cadena de suministros de oro colombiana. minería aurífera en Antioquia. Disponible en Internet: https://mneguidelines. oecd.org/Antioquia-Colombia-Gold-Baseline-SP.pdf Consultado 28.11.2017.

15. ROCHA, Catalina y ESCOBEDO, Rodolfo. (2013). FARC en las periferias: Tumaco, un caso más. Disponible en Internet: http://www.ideaspaz.org/publications?tag=89 Consultado 25.10.2017.

16. TRUJILLO, Augusto y PÉREZ, Guillermo. (2016). El ordenamiento territorial en clave de paz: más allá de La Habana (pp. 158-160). En: RESTREPO, Darío y FLÓREZ, Guillermo. Serie Rutas para la Paz. Diseños institucionales gobernanza territorial para la gestión territorial de la paz. Bogotá: Fundación Konrad Adenauer Stiftung.

17. COLOMBIA. Unidad de Planeación Minero - Energética. (2014). Estudio de la cadena del mercurio en Colombia con énfasis en la actividad minera de oro. Disponible en Internet: https://bdigital.upme.gov.co/bitstream/001/1315/4/ v.2.pdf Consultado 30.03.2018.

Para citar este artículo:
ORTIZ, Jorge Iván. (2019). Reflexiones sobre minería, post-acuerdo y territorialidad. Relación con los nuevos escenarios del post-acuerdo en Colombia. En: Teuken Bidikay, Vol. 10 No 14. Medellín: Politécnico Colombiano. Pp. 213-233. doi:10.33571/teuken.v10n14a10

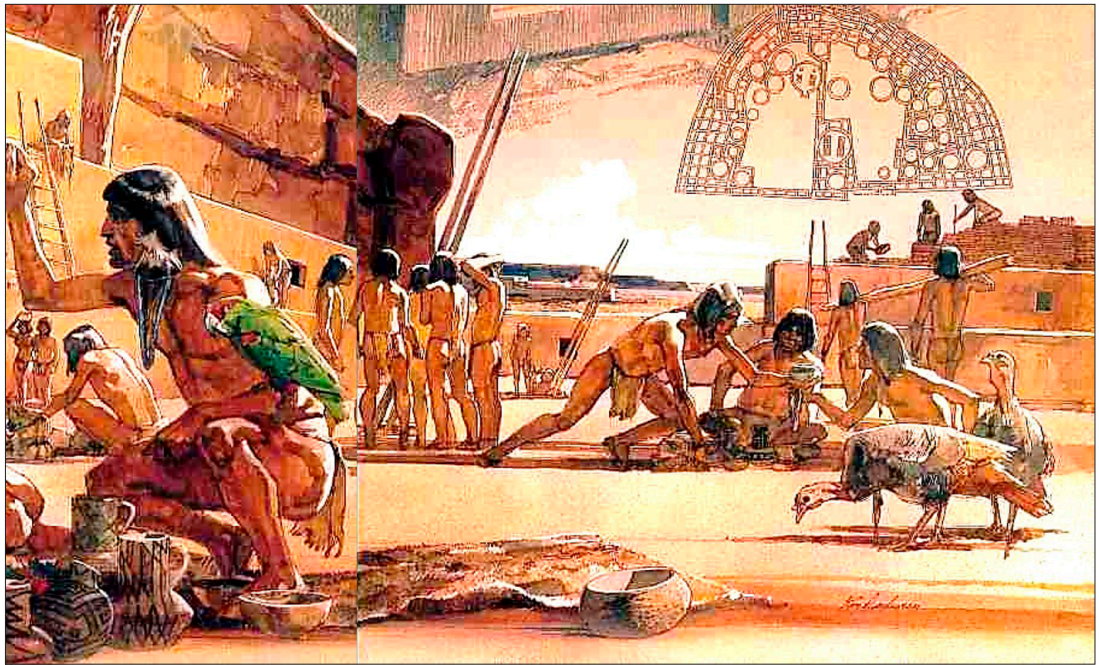


Conformado por una cantidad considerable de emigrantes de la civilización Tolteca, los Pipiles huyeron de Méjico como consecuencia del colapso del Imperio de Tala y se asentaron en las zonas central y occidental de El Salvador. Desde allí resistieron la asimilación hasta 1932, cuando se produjo un levantamiento campesino que fue reprimido por el gobierno militar, dando como resultado un genocidio indígena que afectó principalmente a esta población. Los pocos que quedaron, se vieron obligados a ocultar su identidad cultural y su lengua náhuatl, que habían mantenido viva a pesar del proceso de colonización española. Esta comunidad rendía culto a Tlaloc, dios de la lluvia y a Xipe-totec, al que se le atribuyen sacrificios humanos; su religión tenía directa relación con el ciclo vital del nacimiento, la vida y la muerte. Los pipiles son una muestra tangible de la riqueza cultural de El Salvador; sus artesanías y las ruinas de Cihuatán son una valiosa muestra de ello.

Laura Guzmán M. Politécnico Colombiano.

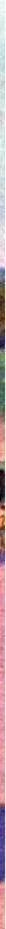

